九州大学学術情報リポジトリ

Kyushu University Institutional Repository

\title{
WEAR PERFORMANCE OF THE MOORING CHAIN USED IN FLOATING WIND TURBINES
}

Gotoh, Koj i

Department of Marine Systems Engineering, Faculty of Engineering, Kyushu University

Murakami, Koji

Department of Civil and Structural Engineering, Graduate school of Engineering, Kyushu University

Nakagawa, Masataka

Department of Civil and Structural Engineering, Graduate School of Engineering, Kyushu University : Master course student

Utsunomiya, Tomoaki

Department of Marine Systems Engineering, Faculty of Engineering, Kyushu University

http://hdl. handle. net/2324/4753059

出版情報: Proceedings of the ASME 2017 36th International Conference on 0cean, Offshore and Arctic Engineering: OMAE2017, 2017-09-25. The American Society of Mechanical Engineers : ASME バージョン:

権利関係 : Copyright $\odot 2017$ by ASME 
OMAE2017-62195

\section{WEAR PERFORMANCE OF THE MOORING CHAIN USED IN FLOATING WIND TURBINES}

\author{
Koji Gotoh \\ Department of Marine Systems Engineering, \\ Faculty of Engineering, Kyushu University \\ 744 Motooka, Nishi-ku, Fukuoka \\ 819-0395, Japan \\ Tel: +81-92-802-3457 \\ Fax: +81-92-802-3368 \\ E-mail: gotoh@nams.kyushu-u.ac.jp \\ Masataka Nakagawa \\ Master course student, \\ Department of Civil and Structural Engineering, \\ Graduate School of Engineering, \\ Kyushu University \\ Tel: +81-92-802-3464 \\ Fax: +81-92-802-3368 \\ Email: 2TE16294N@s.kyushu-u.ac.jp
}

\author{
Koji Murakami \\ Department of Civil and Structural Engineering, \\ Graduate school of Engineering, \\ Kyushu University \\ 744 Motooka, Nishi-ku, Fukuoka \\ 819-0395, Japan \\ Tel: +81-92-802-3464 \\ Fax: +81-92-802-3368 \\ Email: murakami@nams.kyushu-u.ac.jp \\ Tomoaki Utsunomiya \\ Department of Marine Systems Engineering, \\ Faculty of Engineering, Kyushu University \\ 744 Motooka, Nishi-ku, Fukuoka \\ 819-0395, Japan \\ Tel: +81-92-802-3447 \\ Fax: +81-92-802-3368 \\ Email: utsunomiya@nams.kyushu-u.ac.jp
}

\begin{abstract}
To produce offshore wind power generation plants, deep-sea floating wind turbine facilities are required. Commercial installation of floating wind turbine facilities requires a reduction of the mooring cost. Mooring chain breaks due to progressive wear will lead to enormous damages. Therefore, a quantitative wear evaluation method for mooring chains needs to be established. In this study, an experimental setup was constructed to reproduce the wearing phenomenon in mooring chains due to the motion of the floating body induced by waves, and its usefulness was confirmed. The result of the wear test conducted in this study suggests that the tensile force between links affects the degree of wear. Additionally, numerical simulations were performed using a finite element model with measured wear characteristics of the link material to reproduce the phenomenon of wear between links and confirmed that the wear phenomenon could be represented by numerical simulation.
\end{abstract}

\section{INTRODUCTION}

To reduce greenhouse gas emissions, renewable energy is needed to serve as a replacement for fossil fuels. Wind power generation is expected to play a significant role in this process. This is especially true for offshore wind power generators, which are capable of stable and efficient power generation because the offshore wind speed is stronger and its variation is smaller than on land. To deploy offshore wind power generation plants, deepsea floating wind turbine facilities are essential.

The wear performance of mooring chains was reported by Yaghin and Melchers [1]. Tests were performed on stud link chain with a cross sectional diameter of $16 \mathrm{~mm}$. In these tests, the chain motion that caused the wear was produced by considering the behavior of mooring chains connected to the floating production storage and off-loading (FPSO) vessels. They confirmed that the tensile force between the links had a significant and nonlinear effect on the inter-link wear. However, their experiments were small scale and they did not report the estimation procedure for the amount of wear. Brown et al. [2] proposed a practical method to estimate wear and corrosion of mooring chains based on calibration with field measurements. However, the estimate from this method is dependent on the calibration determined from the specific moored area. 
The purpose of this work was to develop a wear estimation procedure that considers the theoretical background of the phenomenon. In this study, an experimental setup to reproduce the inter-link wear in actual scale was developed. In addition, numerical simulations using finite element analysis with measured wear characteristics of the materials were performed to reproduce the phenomenon of wear between links.

\section{DEVELOPMENT OF EXPERIMENTAL SETUP}

We developed an experimental setup to reproduce the interlink wear that is induced by the motion of the mooring chain. The specifications of the setup are as follows.

1) Two connected studless link chain were adopted as the test objects.

2) Constant inter-link force and sliding was applied.

3) Experiments were performed in dry air conditions.

To replicate in-service conditions, the experiments should be performed in seawater. However, the experiments in this study were performed in dry air for the following reasons.

1) More severe experimental conditions were achieved in dry air because of abrasion pieces between the links contact surfaces. In seawater, such pieces will be washed away.

2) At present, the abrasive wear caused by the sand or gravel embroiled between the link contact surfaces is ignored. The mooring system [3] we developed for the floating wind turbine behaves similarly to the tensile mooring state. However, the wearing caused by embroiled sand or gravel was observed at the seabed touchdown region in the standard relaxed mooring system [4].

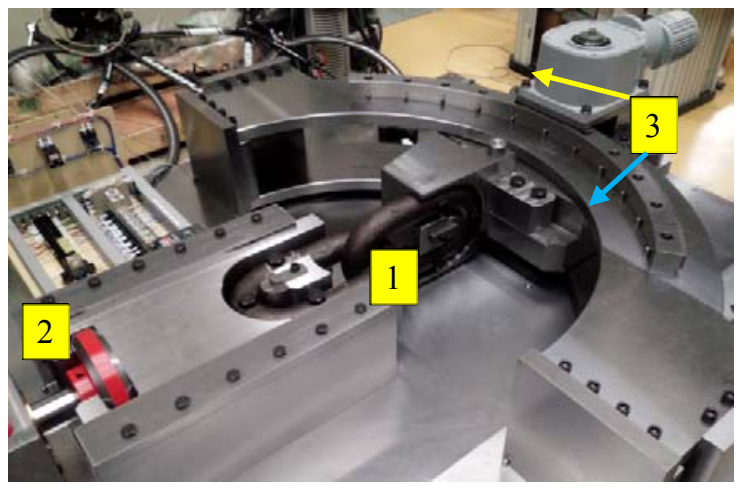

FIGURE 1 OVERVIEW OF MOORING CHAIN WEAR TEST SETUP.

An overview of our experimental setup is shown in Fig. 1. The test links were connected at location 1. The left link was mounted horizontally and was pulled by the hydraulic equipment, at location 2. Sliding movement between the links was achieved by using the attached arc-shaped rack and pinion motor, shown at location 3 . The radius of the arc-shaped rack was $588 \mathrm{~mm}$, and the moving arc angle was 90 degrees. One round trip period of the pinion was $243 \mathrm{~s}$.

\section{WEAR TEST}

Wear tests were performed by utilizing the experimental setup described above. The studless links were made of Grade R3S mooring chain classified by ABS [5]. Minimum breaking strength (MBS) of the link was 3,514 kN. The shape of the unit link is shown in Fig. 2.
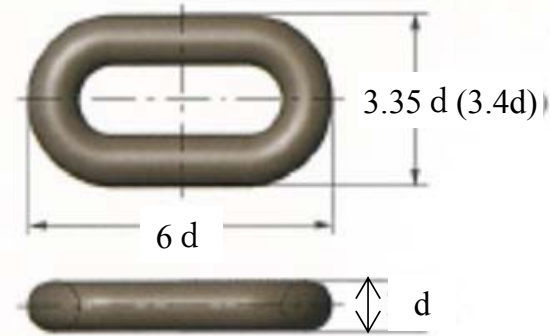

FIGURE 2 SHAPE OF THE STUDLESS LINK ( $d=60 \mathrm{~mm})$.

Tensile force during the test was set at $60 \mathrm{kN}$, which corresponds to $1.7 \%$ of the MBS of the link. This force was chosen for the following reasons.

1) The average tension between the mooring chain of inservice FPSOs is about $3-6 \%$ of MBS [1].

2) If the tensile load is increased, chain sliding will be restricted, and the chain will be subjected to bending fatigue instead of wear [6]-[8].

Figure 3 shows the wear progression that occurred in the test chains during the experiment. The average wear weight per sliding cycle is shown in Fig. 4.

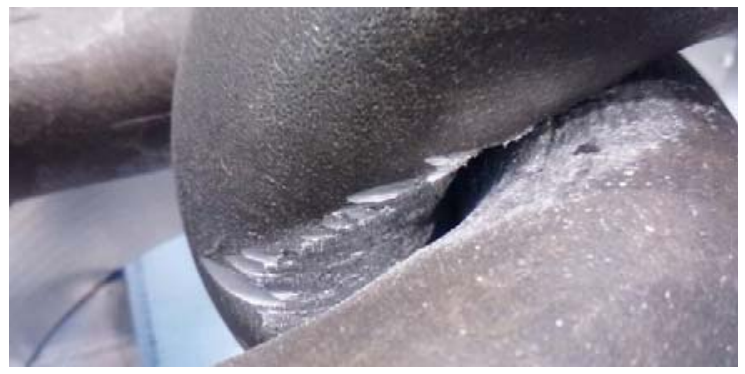

(a) Number of sliding cycles: 21-350.

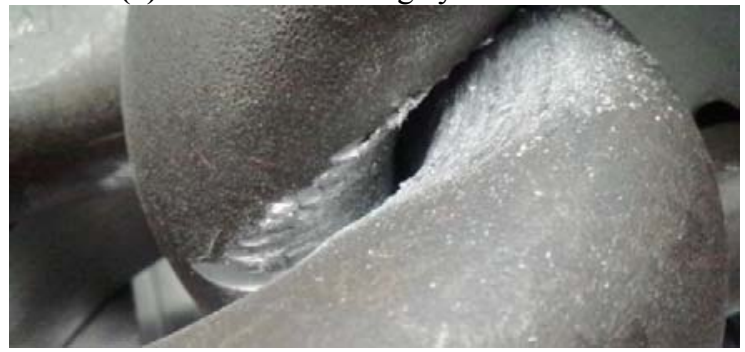

(b) Number of sliding cycles: 351-400. 


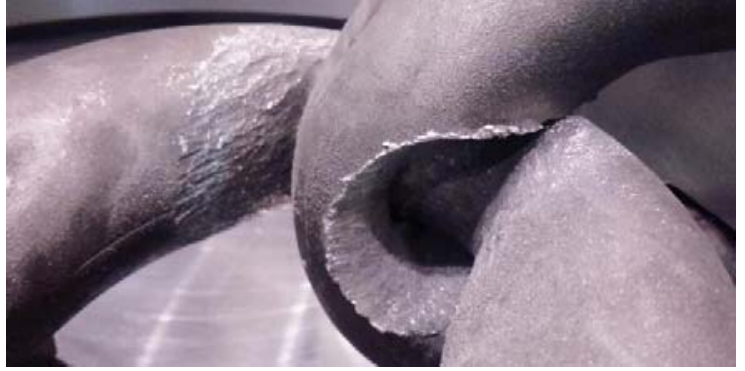

(c) Number of sliding cycles: 4,300 (end of the experiment).

\section{FIGURE 3 WEAR EVOLUTION OF LINKS IN THE EXPERIMENT.}

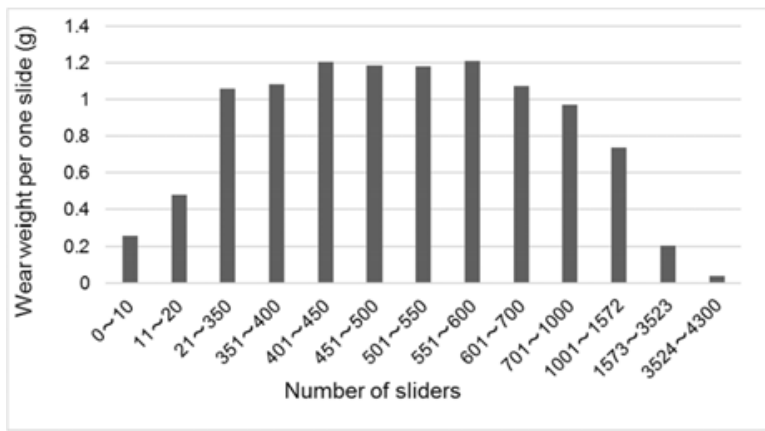

FIGURE 4 WEAR WEIGHT PER SLIDING CYCLES.

The amount of wear weight increased and converged with increasing sliding cycles. After 600 cycles, the wear weight per cycle gradually decreased, and it sharply decreased after 1,500 cycles.

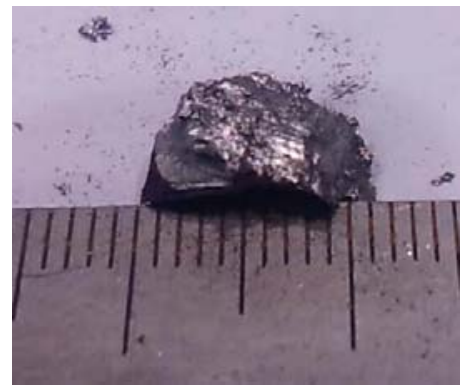

\section{FIGURE 5 LARGE ABRADED PIECE GENERATED AT THE EARLY STAGE OF THE EXPERIMENT.}

At the outset of the experiment, large abraded pieces were generated, an example of which is shown in Fig. 5. It is thought that these large pieces were generated by delamination fracture on the contact surfaces. This fracture might occur for the following reasons.

1) At the onset of the experiment, the contact condition between the links was a surface contact rather than a point contact because the shape of the bent section of the links was not a perfect circle. Small wear debris generated in the early stages of the experiment may have entered the contact surfaces and was then followed by the surface delamination.

2) Constraints between the links reduced smooth sliding, and the delamination fracture on the link surfaces occurred because of the relative relationship between the hardness of the material and the ability of the links to slide and deform.

If these large abraded pieces are generated in-service, large fresh contact surfaces are generated and the corrosion of links would be enhanced. However, currents may wash the abraded pieces away. The role of the abraded pieces on the wear evolution and the structural integrity of the mooring chain have not been measured until now.

The wear weight sharply decreased after 1,500 cycles, because of insufficient pulling allowance in the experimental setup. Figure 6 shows the evolution in the pulling allowance in the setup. It is confirmed from Fig. 6 that the allowance was reduced as the experiment progressed, and was completely reduced after about 1,500 cycles.

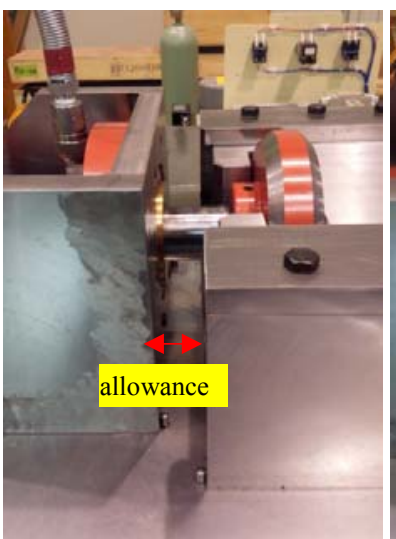

(before experiment)

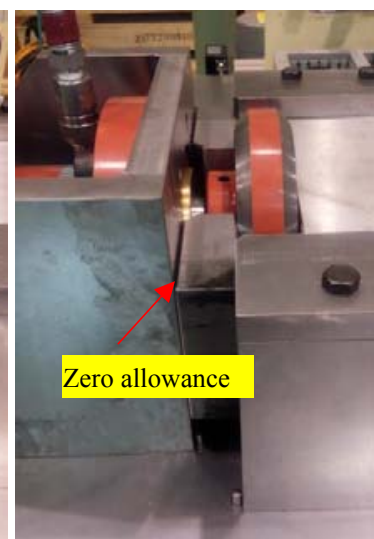

(after 1,500 cycles)
FIGURE 6 PULLING ALLOWANCE OF THE TESTING MACHINE.

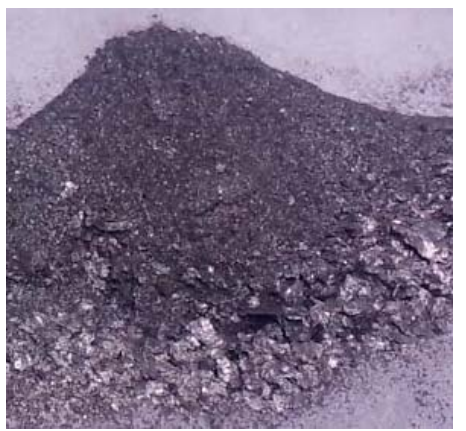

FIGURE 7 WEAR PARTICLES GENERATED DURING CYCLES 1,573-3,523.

Figure 7 shows the wear particles generated during cycles 1,573-3,523 of the experiment. The large particles, which were on the order of a few millimeters in size, shown in the front of the photograph were generated during the early stages of the 
experiment. The small powdery particles, which were on the order of about $0.1 \mathrm{~mm}$ in size, shown in the back of the photograph, were generated after the halfway point in the experiment. It is thought that the wear mechanism changed from severe to mild wear as the experiment progressed by reducing the tensile force between the links.

\section{REPRODUCTION OF THE EXPERIMENT BY FINITE ELEMENT ANALYSIS}

When designing floating wind turbines, the tensile force and sliding range generated in the mooring chain can be estimated by a wave response analysis for the floating body. The wearing behavior of the mooring chain can then be estimated from the tensile force and sliding range histories derived from the response analysis.

In this section, the chain wear experiment was reproduced numerically using nonlinear finite element analysis (FEA), including element contact effects. To perform an FEA including the wear performance of the materials, the wear coefficient of the material must be identified. The pin-on-disk wearing test, which is a common wear performance test, was performed to obtain the wear coefficient of the material. Uniform rotary motion or rotary reciprocating motion can be used in the pin-on-disk wearing test. In this study, the rotary reciprocating motion was selected to measure the inter-link behavior. The angle of the rotary reciprocating motion was set to 90 degrees. Values of the wear coefficient in each experiment were identified by the following equations [9]

$$
\begin{gathered}
K=H W_{S} \\
W_{S}=\Delta W / P L \rho
\end{gathered}
$$

where,

$K$ : Wear coefficient $\left[\mathrm{mm}^{2} / \mathrm{N}\right]$,

$H$ : Vickers hardness,

$W_{s}: \quad$ Specific wear rate $\left[\mathrm{mm}^{2} / \mathrm{N}\right]$,

$\Delta W:$ Amount of mass decrease by the wear $[\mathrm{g}]$,

$P: \quad$ Applied load [N],

$L: \quad$ Sliding distance $[\mathrm{mm}]$, and

$\rho$ : $\quad$ Material density $\left[\mathrm{g} / \mathrm{mm}^{3}\right]$.

Table 1 shows the measured wear coefficient of the link material derived from 14 experiments. In general, the wear coefficient and the specific wear rate show large scatter. The amount of scatter in the measured wear coefficient was similar to the results of round robin tests of steels performed by the Japan Society of Mechanical Engineering [10].

TABLE 1 WEAR COEFFICIENT OF THE LINK.

\begin{tabular}{lll}
\hline Maximum value: & $7.93 \times 10^{-4}$ & $\mathrm{~mm}^{2} / \mathrm{N}$ \\
\hline Minimum value: & $6.30 \times 10^{-6}$ & $\mathrm{~mm}^{2} / \mathrm{N}$ \\
\hline Average: & $8.36 \times 10^{-5}$ & $\mathrm{~mm}^{2} / \mathrm{N}$ \\
\hline
\end{tabular}

The commercial finite element software package MSC Marc 2015 [11] was used in this study. The wear equation proposed by Archard [12] was implemented in MSC Marc as the governing equation of the wear.

$$
W=(K / H) \sigma V_{\text {rel }}
$$

where,

$$
\begin{array}{ll}
W: & \text { Wear rate on each finite element node }[13][\mathrm{mm} / \mathrm{s}], \\
K: & \text { Wear coefficient }\left[\mathrm{mm}^{2} / \mathrm{N}\right] \\
H: & \text { Vickers hardness, } \\
\sigma . & \text { Contact stress on wear surfaces }\left[\mathrm{N} / \mathrm{mm}^{2}\right] \text { and } \\
V_{\text {rel }}: & \text { Relative sliding speed on contact surfaces }[\mathrm{mm} / \mathrm{s}] .
\end{array}
$$

Mesh subdivision and model information are shown in Fig. 8. Material constants used in the FEA are shown in Table 2. The contact that results from the application of a proof load [14] was not included in the model. Application of an initial proof load could potentially increase the contact area and cause both contact stresses and wear area, which affects the wear computations. This will be considered in future studies.

\begin{tabular}{ll} 
TABLE 2 MATERIAL PROPERTIES OF THE LINK. \\
\hline Young's modulus: & $206,000 \mathrm{MPa}$ \\
\hline Poisson's ratio: & 0.3 \\
\hline Tensile strength: & $770 \mathrm{MPa}$ \\
\hline Yield strength: & $490 \mathrm{MPa}$ \\
\hline Elongation: & $15 \%$ \\
\hline Density & $7.85 \times 10^{-3} \mathrm{~g} / \mathrm{mm}^{3}$ \\
\hline Vickers hardness & $307.9 \mathrm{Hv}$ \\
\hline
\end{tabular}

Numerical simulation results are shown in Fig. 9. Three wear coefficient values were used in these analyses. Red and blue curves shown in these figures represent the wear histories of the red and blue model components shown in Fig. 8. Black curves represent the total wear weight. The "Uactive" user subroutine implemented in MSC Marc was used to remove the contact elements when the amount of wear volume exceeded the element volume. Estimated wear weight per cycle is summarized in Table 3. For the validation of estimated wear weight, measured wear weight is summarized in Table 4. 


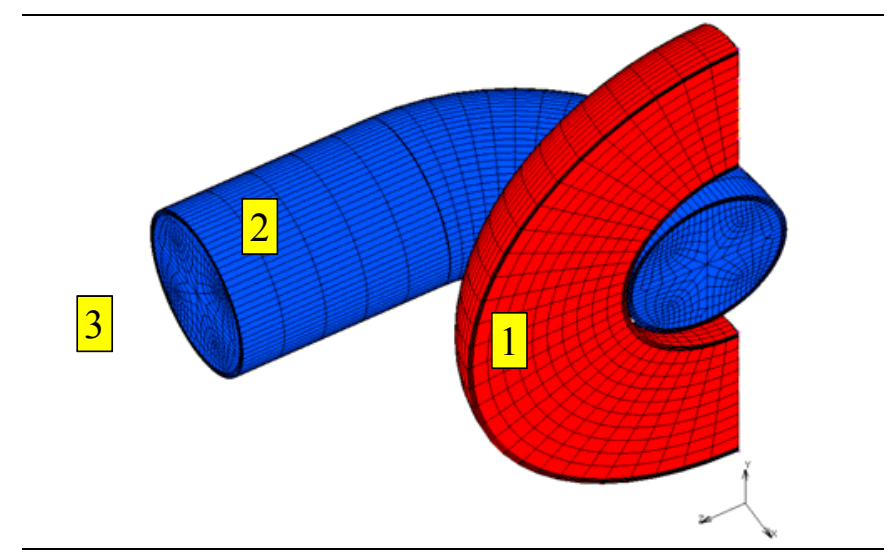

Number of Nodes: 26,257

Number of Elements: 25,900

Minimum element size $(x-y-z)$ :

$4.4 \mathrm{~mm}-2.4 \mathrm{~mm}-0.4 \mathrm{~mm}$

Element type: 8 nodes hexahedral

Boundary condition:

$x$-direction displacement was fixed on surface 1 .

$x$ - and $y$-direction displacement of the whole blue body was fixed.

Tensile loading on the $z$-direction of surface 3 .

Chain sliding method:

Rotating body $1 \pm 45$ degrees around the $x$-axis while applying the tensile force to surface 3 .

\section{FIGURE 8 FINITE ELEMENT SUBDIVISION AND BOUNDARY CONDITIONS USED.}

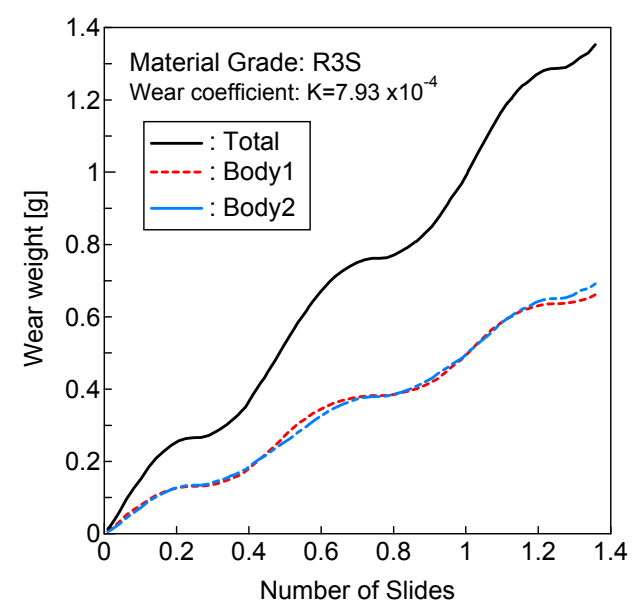

(a) Wear coefficient is $7.93 \times 10^{-4} \mathrm{~mm}^{2} / \mathrm{N}$

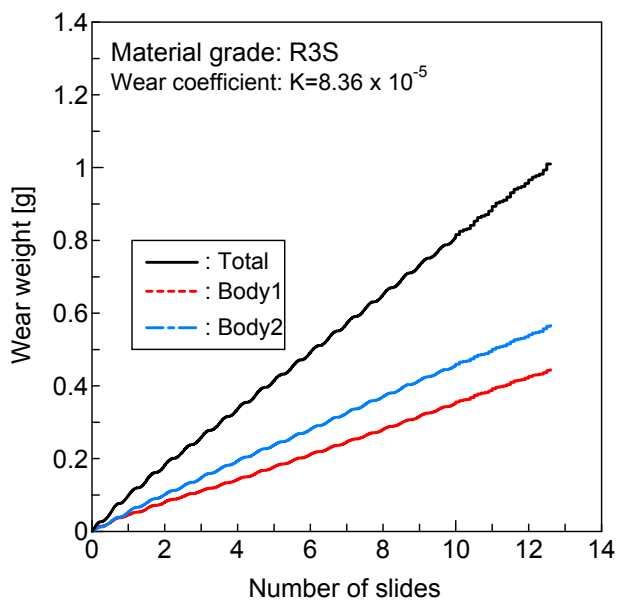

(b) Wear coefficient is $8.36 \times 10^{-5} \mathrm{~mm}^{2} / \mathrm{N}$

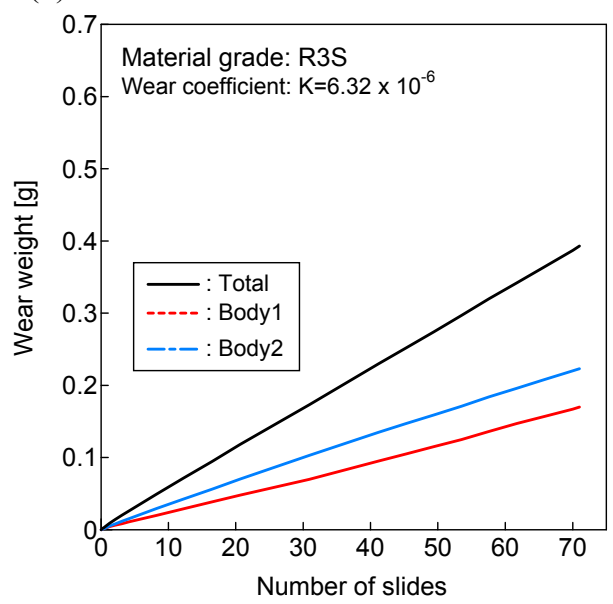

(c) Wear coefficient is $6.32 \times 10^{-6} \mathrm{~mm}^{2} / \mathrm{N}$ FIGURE 9 WEAR WEIGHT ESTIMATION FROM THE FINITE ELEMENT ANALYSIS.

TABLE 3 ESTIMATED WEAR WEIGHT PER CYCLE.

\begin{tabular}{cc}
\hline Wear coefficient $\left[\mathrm{mm}^{2} / \mathrm{N}\right]$ & Wear weight per one slide $[\mathrm{g}]$ \\
\hline $7.93 \times 10^{-4}$ & $1.29(0.921$ cycle $)$ \\
\hline $8.36 \times 10^{-5}$ & 0.531 \\
\hline $6.32 \times 10^{-6}$ & 0.0186 \\
\hline
\end{tabular}

[Note] Estimated wear weight shown in Table 3 in the case when the wear coefficient was highest is the total weight during the numerical simulation, because the FEA was terminated at 0.921 cycles.

TABLE 4 MEASURED WEAR WEIGHT PER CYCLE.

\begin{tabular}{cc}
\hline Measured sliding cycle & Wear weight per one slide $[\mathrm{g}]$ \\
\hline $1-10$ & 0.26 \\
\hline $1-20$ & 0.37 \\
\hline $1-350$ & 1.018 \\
\hline
\end{tabular}


It was confirmed from Tables 3 and 4 that the wear weight during the early stage of the experiment could be estimated if the average value of the wear coefficient was used in the FEA. It should be noted that all of the simulations were terminated, and the reason for the termination is currently under investigation. One possibility is insufficient application of element removal when a large amount of wear occurred at contact surfaces. In addition, insufficient numerical resources were available to perform nonlinear contact analysis.

\section{CONCLUSIONS}

An experimental setup was developed to reproduce interlink wear in actual scale. In addition, FEA was used to reproduce the experiment, and the early stage of the experiment was successfully reproduced. However, the full experiment was unable to be simulated. Future research directions are as follows.

1) Performing wear tests under various tensile loads to clarify the effect of tensile loading on the wear.

2) Improving the numerical model to reproduce the inter-link wear under in-service conditions.

3) Development of a practical and simple wear estimation procedure.

\section{ACKNOWLEDGMENTS}

This research was supported by the Low Carbon Technology Research and Development Program (FY2015-FY2017), Ministry of the Environment, Japan.

\section{REFERENCES}

[1] Yaghim, A.L. and Melchers, R.E., 2015, Long-term interlink wear of model mooring chains, Marine Structures, 44, pp.61-84.

[2] Brown, M.G., Comley, A.P, Eriksen, M., Williamns,I., Smedley, P., Bhattacharjee, S., 2010, Phase 2 Mooring Integrity JIP -Summary of Findings, Proceedings of OTC, OTC 20613.

[3] Utsunomiya, T., et al., 2016, At-sea Demonstration Test for Cost-reduction of Mooring System for Floating Wind Turbine, Proceedings of WWEC2016, B-4-5.

[4] Aso, Y. and Hashimoto, S., 2015, Strength and wear characteristics of the buoy mooring chain, Bulletin of JASNAOE, 62, pp.11-14 (in Japanese).

[5] American Bureau of Shipping, 1999, Guide for Certification of Offshore Mooring Chain.

[6] Rampi, L., et al., 2016, Chain Out of Plane Bending (OPB) Fatigue Joint Industry Project (JIP) Static Test Program and OPB Interlink Stiffness, Proceedings of OMAE 2016, OMAE2016-54195.

[7] Rampi, L., et al., 2016, Chain Out of Plane Bending (OPB) Fatigue Joint Industry Project (JIP) FEA Results and Multiaxiality Study Results, Proceedings of OMAE 2016, OMAE2016-54198.

[8] Rampi, L., et al., 2016, Chain Out of Plane Bending (OPB) Fatigue Joint Industry Project (JIP) Fatigue Test Program
Results and Methodology, Proceedings of OMAE 2016, OMAE2016-54199.

[9] For example, Sasada, T., 2008, Wear, Yokendo, ISBN: 9784-8425-0433-9 (in Japanese).

[10] Japan Society of Mechanical Engineering, 2010, JSME S013-2010: Standard test procedure of the wear, pp.38-52.

[11] http://www.mscsoftware.com/product/marc (Accessed on March 26, 2017.)

[12] Archard, J.A., 1956, Contact and Rubbing of Flat Surface, J. of Applied Physics, 24, pp. 981-988.

[13] MSC Marc 2015 Manual Volume A: Theory and User Information, 2015, pp.210-212.

[14] Vargas, P.M. and Jean, P., 2005, FEA of Out-of-Plane Fatigue Mechanism of Chain Links, Proceedings of OMAE 2005, OMAE2005-67354 